\title{
Social implications of palm oil production through social life cycle perspectives in Johor, Malaysia
}

\begin{abstract}
Purpose: Palm oil is considered as the primary source of income for many farmers in Southeast Asia and become a very important agricultural commodity for the Malaysian economy in recent years. Besides its main usage as cooking oil, it is also exported to be used in many commercial foods and personal care products, as well as biofuels productions (Wong et al. Pertanika Journal of Scholarly Research Reviews 1:33-39, 2015). Over the years, the agricultural sector, especially the livestock and dairy sectors in particular, has been increasingly criticized for their environmental as well as social impacts (Revéret et al. 2015). However, while the products of the agricultural sector contributed significantly to the economic mainstay, the social aspects of it especially those associated with the workers, communities, and environment are equally important and often neglected. The purpose of this research is to identify potential social impacts (implications on workers and local community) throughout the whole life cycle of palm oil production using the Social Life Cycle Assessment (S-LCA) methodology. Methods: The methodology of this study consisted of several steps in the framework of the Life Cycle Assessment (LCA) study. The steps involved were goal and scope definition, Life Cycle Inventory (LCI) analysis, Life Cycle Impact Assessment (LCIA), and interpretation. Descriptive analyses that involved the social impact associated with the operation of palm oil mill, local community, and workers were used. In order to acquire information from these stakeholders, two sets of questionnaires were constructed based on the subcategories proposed by UNEP (2009). Results and discussion: The results on social aspects showed that the workers exhibited high value of satisfaction regarding social benefits conferred upon them such as annual leave, panel clinic, Employees Provident Fund (EPF), Social Security Organization (SOCSO) scheme, and public holidays. Meanwhile, the satisfaction level of the local community is different according to specific categories. For instance, a small percentage of satisfaction exists among the local community regarding the palm oil industry especially in heritage and cultural conservation. Conclusions: Findings from the S-LCA analysis are positive as palm oil production still met the required criteria in terms of social significance to those who are in direct contact with this operation especially the workers and local community.
\end{abstract}

Keyword: Local community; Palm oil industry; S-LCA; Social impact from palm production; Workers 